\title{
Digital Platforms as Public Utilities
}

\author{
Vicente Bagnoli
}

Published online: 17 September 2020

(C) Max Planck Institute for Innovation and Competition, Munich 2020

The rise of digital platforms and the relevance they have in the structure of the market have resulted in a novel significance that goes beyond their being mere "facilitators" or "intermediaries", becoming an actual essential facility, which could define the role of digital platforms as public utilities.

Platforms in the digital economy (or two-sided markets and even multi-sided markets) have been increasing enormously in number and relevance for the interaction of different groups of customers, such as consumers or users of the services provided by the platform, advertisers who display advertisements to consumers on the platform, and content creators, such as news outlets.

The speed and extent of growth in the digital economy has been crucial in making digital platforms one of the most significant, demanding and investigative challenges faced by regulators and competition authorities around the world. These platforms disintermediate the so-called ordinary markets to connect users directly, thus making these markets even more intricately multi-sided. This has led to a wielding of massive control over commerce, communications and public speech.

The widespread and frequent use of digital platforms throughout the world demonstrates that their innovative and popular services offered to customers have transformed the way users communicate with each other, access news and information, and interact with other groups of customers or individuals. But the impact of digital platforms on competition and consequently on society warrants a careful analysis.

If on the one hand digital platforms can offer substantial benefits to consumers and businesses, on the other hand they act as global super-platforms whose rapid

Vicente Bagnoli is Professor of Law at Mackenzie Presbyterian University, São Paulo; visiting researcher (2015) Post Doc at the Max Planck Institute for Innovation and Competition, Munich; and Director of the ASCOLA chapter Brazil.

\footnotetext{
V. Bagnoli ( $₫)$

Professor of Law at Mackenzie Presbyterian University, São Paulo, Brazil

e-mail: bagnoli@vicentebagnoli.com.br
} 
rise to dominance is related to network effects, high switching costs and an extraordinary ability to extract, control and analyze data. Their functioning as gateways or even gatekeepers indicates that they are essential facilities.

What makes digital platforms so unique is Big Data, the use of which promotes a feedback loop, allowing companies to create products and offer services that will attract current as well as new customers. This assures substantial economies of scale and drives the market in favor of the already dominant platforms, who not only take part in a myriad of businesses such smartphones, e-commerce and digital payments, but also are suspects of involvement in the infringement of data privacy, misinformation, labor issues and election interference.

The major advantage of businesses that have built digital platforms in the datadriven economy is confirmed by the UN Conference on Trade and Development (UNCTAD) in its "Digital Economy Report". ${ }^{1}$ By acting as both intermediary and infrastructure, the platforms are in the position to record and extract data related to online actions, interactions and transactions by users. Microsoft, Apple, Amazon, Google, Facebook, Tencent and Alibaba, the so-called Big Seven "superplatforms", account for two thirds of the total market value of the top 70 platforms.

But what else do those big techs have in common? They have been consolidating their competitive positions by acquiring potential competitors, increasing their presence into complementary products or services, starting strategic partnerships with leading corporations in traditional markets, and lobbying in policymaking spheres nationally and globally. Last but not least, the Covid-19 pandemic has been further strengthening the market power of big tech platforms and the dependence society has on them.

Considering the market power that mega-platforms have around the world, the analysis of some regulatory and competition-related topics is essential to understand whether, and if so how, regulators and competition authorities should intervene in digital platforms. These topics include market definition, market power, vertical assessment, assessment of anti-competitive effects, whether innovation has been stifled, and data as an input for platforms.

A more effective competition law enforcement on the dominant digital players could be implemented by properly defining the Big Data Relevant Market (BDRM). It could explain the whole picture of the digital market in its different stages.

Identifying and understanding the BDRM structure (Big Data capture, Big Data storage and Big Data analytics) from the competition law perspective may also lead to better comprehension of the performance of digital platforms and verify precise competition issues such as market power, barriers to entrance and abuses of dominance.

The BDRM points out that the Big Data cycle not only deals with horizontal overlaps, but also with vertical ones, which reveals existing or potential enhancements of market power and dominance.

The precise identification of the players and their respective shares in the capture, storage and analysis of Big Data better explain how concentrated a digital market is.

\footnotetext{
${ }^{1}$ https://unctad.org/en/PublicationsLibrary/der2019_en.pdf (accessed 29 July 2020).
} 
This is especially true since one player can perform its business in only one or even in all three stages of the BDRM, which commonly is the case of super-platforms.

The platforms' ecosystem deals with services, products, ideas and democracy, the access to which has become essential for communities, consumers and sellers. The range extends to books, hotels and news, among others, which are not often available elsewhere. Therefore, the ecosystem of digital platforms should be measured similarly to public utilities, since it is an infrastructure of a public-good nature which users rely on.

The dynamics of competition within the ecosystem of the platform are governed and controlled by who owns it. Restriction or exclusion from this utility should not be decided by a single private company. Dominant digital platforms should have to do this with neutrality, and a means to safeguard the neutrality of dominant platforms is to apply the "essential facilities doctrine". Regulation would be a tool to assure open and fair access in the market.

Regulators traditionally act on such markets where competition cannot work effectively when left to itself. A pro-competition market regulation implies different reasons for government intervention in markets by adopting sectorial regulations.

Regulated sectors usually require public services or utilities that are not only necessary for consumer welfare such as price and quality, but also for a company's entrepreneurship such as profit and market entry. Through their actions, regulators have the ultimate scope to promote competition among companies in oligopolized markets or even in natural monopolized markets exploited by the private sector, where competition in the market is not possible.

The dominance and consequently the market power of digital platforms, as addressed by the German Monopolies Commission, ${ }^{2}$ could require a special Platform Regulation which would subject platforms to a ban on self-preferencing and to stricter interoperability and portability obligations as well as additional tailormade solutions with remedies for abuses of dominance causing lasting effects on the market structure.

Bigger and more powerful digital platforms foster greater dependence in society, which leads them to be considered public utilities. This raises the competition law bar and subjects super-platforms to specific regulations.

Publisher's Note Springer Nature remains neutral with regard to jurisdictional claims in published maps and institutional affiliations.

\footnotetext{
${ }^{2}$ https://monopolkommission.de/en/reports/biennial-reports/342-biennial-report-xxiii-competition-2020. html (accessed 29 July 2020).
} 